\title{
Draping simulation-supported framework for cost- and weight- effective composite design
}

\author{
Per Mårtensson* \\ KTH Royal Institute of Technology, \\ Stockholm, Sweden \\ and \\ Volvo Car Corporation, \\ Dept. 93600/PVÖSN23, \\ Gothenburg, Sweden \\ Email: per.martensson@volvocars.com \\ Email: permar@kth.se \\ ${ }^{*}$ Corresponding author
}

Department of Aeronautical and Vehicle Engineering,

\section{Dan Zenkert and Malin Åkermo}

Department of Aeronautical and Vehicle Engineering, KTH Royal Institute of Technology,

Stockholm, Sweden

Email: danz@kth.se

Email: akermo@kth.se

\begin{abstract}
The importance of design for manufacturability when designing composite structures for high-volume automotive applications is great. One key aspect of the producibility and the quality of the final part, as well as the level of complexity of manufacturing operations, are the formability of fibre fabrics. Simulations of this forming, in the composite industry referred to as draping simulations, can greatly improve the manufacturability of the design. Draping simulations will also indicate where areas become too complex, undrapable, to be able to form using one cloth of fabric. In this paper, the draping simulation's undrapable areas are considered as guidance when defining suitable split lines in a composite structure applying a differential design approach. Here, the simulations are located in a greater framework to provide guidelines for a wellbalanced cost and weight-effective composite design, and the integration of draping simulations, as well as the framework, is exemplified in a case study. It is observed that the choice of split lines becomes more methodical and less subjective compared to previous approaches. However, draping simulations today are not optimised for high-volume forming processes, and the work of defining split lines becomes complex. In order not to become too time consuming and complicated, draping simulations are required to use single-step forming processes.
\end{abstract}

Keywords: automotive; composites; cost; manufacturing constraints; multi objective optimisation; weight optimisation. 
Reference to this paper should be made as follows: Mårtensson, P., Zenkert, D. and Åkermo, M. (2017) 'Draping simulation-supported framework for costand weight- effective composite design', Int. J. Automotive Composites, Vol. 3, No. 1, pp.1-13.

Biographical notes: Per Mårtensson is a Technical Specialist at Volvo cars, Advanced Engineering Department and Industrial PhD candidate at The Royal Institute of Technology. His area of research is strategies and conceptual design philosophies for composite automotive body structures. Considering both financial and technical aspect of the field, he has over 10 years of experience in the composite industry ranging from America's Cup yachts and naval applications to the automotive industry.

Dan Zenkert is a Professor in Lightweight Structures since 2001. He has more than 25 years of experience in research and education in the area of composite materials and sandwich structures. His research is in the field of lightweight composite materials encompassing failure and fatigue, damage tolerance aspects, testing methods and design. In recent years, he has worked more on integrated and multidisciplinary design and on multifunctional composite materials.

Malin Åkermo is an Associate Professor in Lightweight Structures with a special interest in process modelling for composites and sandwich manufacturing, a subject she has been active in for more than 20 years. The research covers material modelling for forming simulations, process simulation as well as development of novel manufacturing processes and cost modelling. The work has resulted in roughly 50 publications in international peer-review journals and international conferences.

\section{Introduction}

It is not a news that, in order to obtain a cost-effective design solution, manufacturing issues must be available and carefully considered as early as in the preliminary design and construction of the component. The methodology developed is generally referred to as design for manufacturing (DFM) (Liu and Yang, 2001; Dorf and Kusiak, 1994) and aims to result in a design with improved producibility resulting in more cost efficient production. DFM normally considers mature material systems and manufacturing processes, which is not the case when considering high-volume manufacturing of structural composite components. Nevertheless, the importance of considering producibility in composite design might be even greater since the material is manufactured at the same time as the component and the choice of material system, its structural design and manufacturing process therefore become intimately related (Gandhi, Thompson and Fischer, 1990; Marsden et al., 2011).

The main cost driver for carbon fibre composites in high-volume manufacturing is the material cost (Fuchs et al., 2008; Mårtensson, Zenkert and Akermo, 2015b) in contrast to lower volume industries, e.g., the aircraft industry, where labour intensive manual steps drive up the costs (Gutowski, Henderson and Shipp, 1991). In order to accomplish a 
composite structure which is cost effective in large-scale production series, designs must keep high material utilisation and straightforward pre-operations clearly in focus. Furthermore, the balance between structural design and complexity of manufacturing operations must be examined (Mårtensson, Zenkert and Akermo, 2015b) in order to identify the optimum of highly integral structures and multiple assembled parts differential design.

To assist in the early design phase, a holistic framework (Mårtensson, Zenkert and Akermo, 2015a) has previously been developed with the purpose of defining cost and weight-efficient design philosophies for high-volume composite components in general, however focussing on composite automotive body structures in particular. The hope is that the adoption of the framework will minimise both financial and technical risks when implementing composites in automotive applications. The framework is built on material and process selection strategies as well as cost modelling and structural optimisation. It further proposes a philosophy of dividing structures to improve cost efficiency and, more explicitly, material utilisation. The partitioning analysis included (Mårtensson, Zenkert and Akermo, 2015a) geometric complexity and its impact on composite material utilisation when deciding between an integral or differential design. However, how to define suitable partitions of such structures in order to minimise geometric complexity has been conducted subjectively.

It is necessary to improve this step and account for the initial textile material properties and composite materials in a more sophisticated approach based on draping or forming analysis. Draping simulations and analysis were initially developed to understand the behaviour of the fabrics when covering a non-plane surface and are today an important tool in the composite design process (Klintworth and Long, 2007). Both structural and cost optimisations have been considered in relation to draping simulations (Kaufmann, Zenkert and Åkermo, 2010), and their importance for reaching a costeffective composite design has been highlighted (Knote, 2011). Consequently, the partition chosen must favour part shapes suitable for the material systems chosen and its drapability. FE models can be used for this purpose as described by James (2015) improving the composite design work, however, requiring extensive computational times. Therefore, kinematic models are more suitable to provide quick responses in a design evaluation.

This paper aims to incorporate kinematic draping simulations in order to improve the conceptual design framework presented in the previous work. The objective is to reduce the impact of engineering judgement when defining suitable split lines to reduce the geometric complexity of composite structures. The refined framework is exemplified in a case study dealing with a smaller structural composite part suitable for incorporation into an automotive body. The same composite part has also been processed in a real life, but more traditional, design project where a team of experts (material, design and manufacturing) were challenged with the same case. The final aim of this paper is therefore to discuss the outcome of the holistic framework in relation to the results of the expert team and thereby, in some sense, to validate this framework. 


\section{Method}

The work presented here is based on a previously developed holistic framework providing design guidelines for a cost and weight-efficient composite design, following the routine shown in Figure 1. The framework addresses material and process selection (Mårtensson, Zenkert and Akermo, 2015b), cost modelling and cost estimation for highvolume composite manufacturing, defining ideal component size for cost and weight efficiency based on geometric complexity (Mårtensson, Zenkert and Akermo, 2015a) and the effects on cost and weight of the final structure depending on partitioning and manufacturing constraint strategies.

Figure 1 Overall framework routine with additional draping analysis added

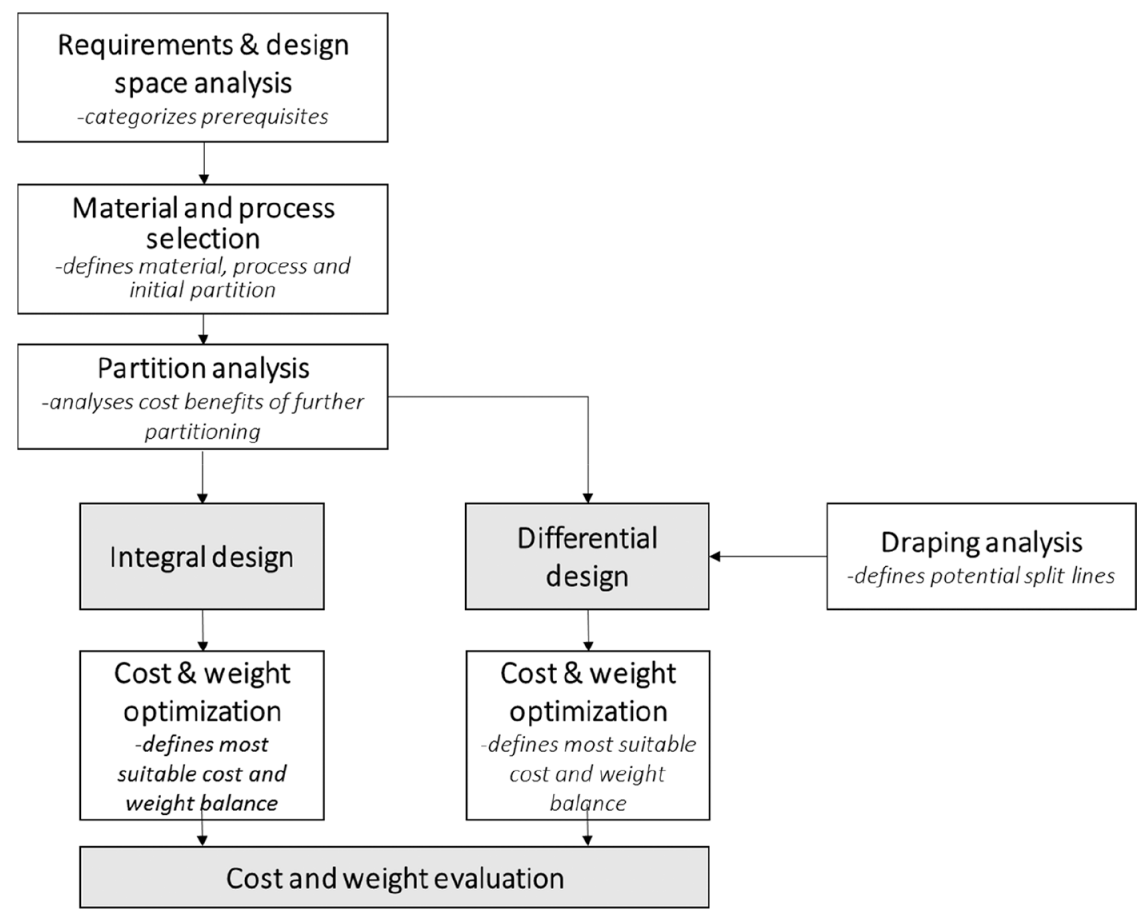

The cost model included (Mårtensson, Zenkert and Akermo, 2015a) is outlined in Figure 2 and briefly described subsequently. The model covers the following material systems and manufacturing processes for high-volume manufacturing; resin transfer moulding (RTM) with epoxy resin and high-strength (HS) carbon fibre fabric, compression moulding (CM) with thermoplastic poly amid resin (PA) with HS carbon fibre, advanced sheet moulding compound (ASMC) with vinyl ester resin and chopped HS carbon fibre. The assembly module for differential designs considers a single and corner overlap adhesive joint with an epoxy adhesive. 
Figure 2 Cost model overall outline for framework processes (see online version for colours)

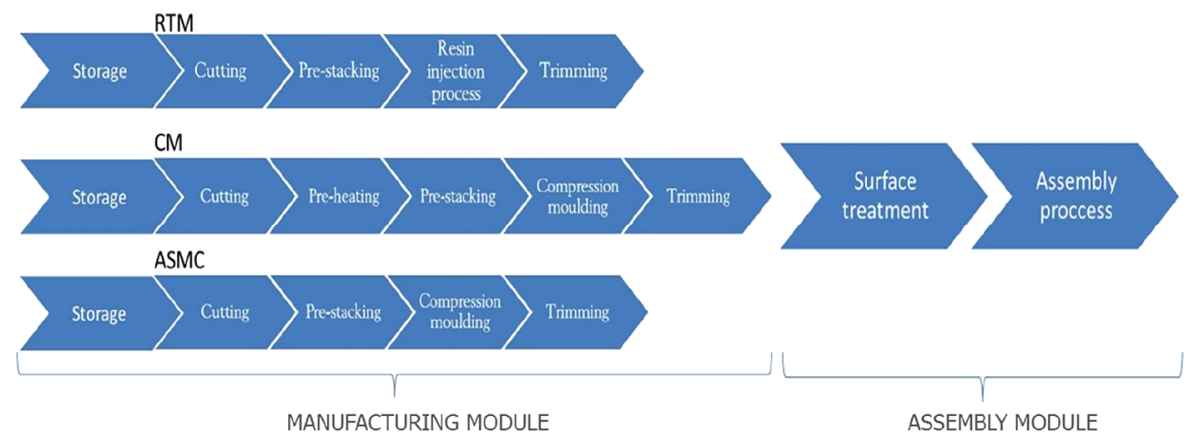

Following the routine in Figure 1, the method is initiated by the requirements and design space analysis, categorisation of the prerequisites into local and global requirements as well as the definition of the design space for the composite structure (Mårtensson, Zenkert and Akermo, 2015b). Based on these requirements and the geometrical shape of the design space, an integrated material and process selection is conducted. The selection method uses cost and weight objective material indices for ranking the suitability of the material and processes for the different requirement areas. Hence, this selection also creates an initial partitioning of the body structure based on the choices of manufacturing methods. Following these steps, a further analysis of the financial benefits of partitioning is conducted, termed the partitioning analysis.

The partitioning analysis, presented in (Mårtensson, Zenkert and Akermo, 2015a), considers a conceptual complexity factor based on the relationship between the complete ( $\left.A_{\text {complete }}\right)$ and the projected area $\left(A_{\text {projected }}\right)$ of the structure analysed, described by the equation

$$
C_{\text {factor }}=A_{\text {complete }} / A_{\text {projected }} \text {. }
$$

as well as the depth of the part geometry. The partition analysis examines whether a structure becomes more cost effective if divided into multiple parts. Partitioning is carried out to improve material utilisation by reducing the geometric complexity, consequently reducing overall cost and simplifying manufacturing operations. In previous work, split lines were positioned according to the engineering judgement (Mårtensson, Zenkert and Akermo, 2015a) to achieve the desired results, i.e., a reduction of geometric complexity. In this work, the method is enhanced with a draping analysis to reduce the impact of subjective selection (Figure 1). Depending on the level of detailed information in the prerequisites, other local and global requirement than those governing the initial material and process selection must be considered in partitioning analysis. These requirements may incorporate, e.g., the necessity for specialised manufacturing operations, multiple attachments or the opportunity to disassemble, etc. These requirements must be analysed in detail by performing a focussed cost estimate considering each specific requirement and, based on that, studying whether further splitting would reduce the cost/weight balance further. This will become clear in the case study presented subsequently.

Draping analysis: in this framework, the draping analysis is used to define the most suitable positioning of the split lines, so that the geometric complexity in relation to the fibre/laminate is reduced. The split lines are defined by the border between drapable and 
non-drapable areas in the simulations, exemplified in Figure 3. Draping simulation algorithms today are based on seed points, a starting point, from where the draping of the fabric is initiated, which simulates hand or robotic lay-up. The drapability is set to a maximum-allowed shear angle in the fabric. Since the positioning of the seed point drastically influences the results of the simulation, as described by Knote (2011), multiple seed points must be studied and consequently multiple splines are defined. In order to reduce the number of split lines, the largest coherent drapable surface area is sought to correlate with the recommended number of parts from the partitioning analysis. Each new part is re-examined for further partitioning, i.e., in the partitioning analysis.

Figure 3 Examples of the draping analysis of an area with different seed points. Potential split lines marked with broken lines (see online version for colours)

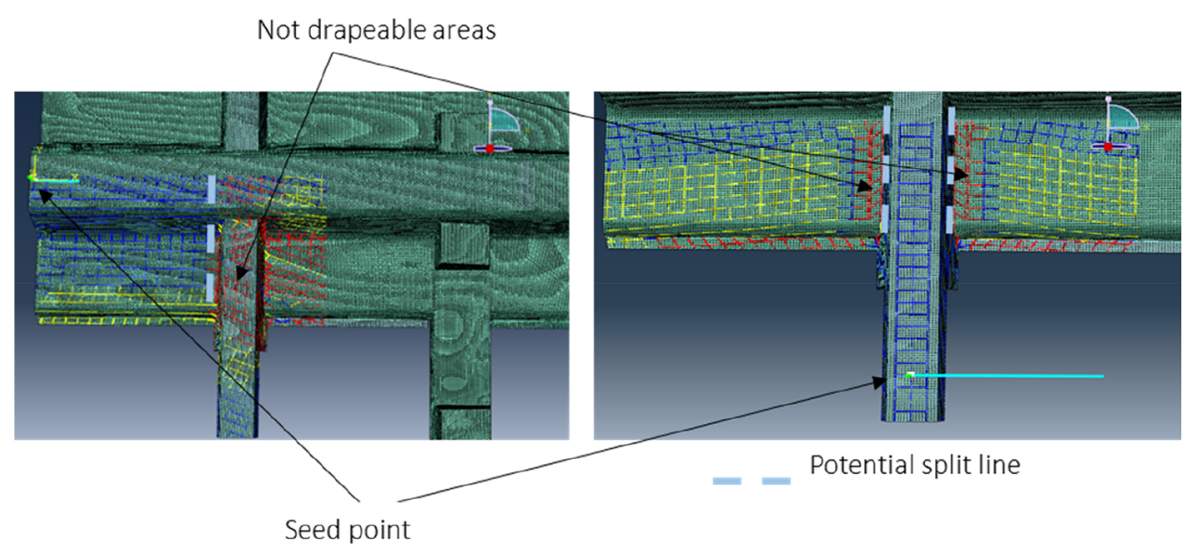

The draping analysis, in addition to split lines, also defines whether the part can be produced in one single preform, or if patching alternatively multiple preforms are required to realise the part.

Finally, a cost and weight evaluation is conducted, and the multi-objective problem of the weight and cost balance is defined by the penalty equation

$$
\text { Minimise } f(v)=C+v^{*} W
$$

where $v$ is the value of weight, i.e., the financial appreciation of a weight decreases, $W$ the weight of the structure and $C$ the cost. W covers additional weight from adhesive single lap joining. The cost, $C$, is rudimentary described as:

$$
C_{\text {tot }}=C_{\text {invest }}+C_{\text {tot_material }}+C_{\text {tool }}+C_{\text {running }} \in \text { assembly, manufacturing }
$$

where:

$C_{\text {invest }}=\mathrm{f}$ (machines, presses, robots, etc.)

$C_{\text {tot } \_ \text {material }}=\mathrm{f}($ material cost $)$

$C_{\text {tool }}=\mathrm{f}$ (tool cost)

$C_{\text {running }}=\mathrm{f}$ (electricity, service, labour, maintenance, etc.)

Both integral and differential designs are evaluated, and a conceptual design is defined as most suitable, with manufacturing processes and material system as well as the most costand weight-efficient number of parts, and the part size are defined. 


\section{Case study}

A case study was conducted and addressed the redesign phase of a floor structure modified for a battery electrical vehicle (BEV). The BEV is targeted for a volume of 20000 vehicles annually. The design space is shown in Figure 4 and consists of the tunnel, two front cross members, two rear cross members and a modified floor section. It is extremely constrained due to the carryover of all the surrounding structure, the adopted load path philosophy and also equipment such as seats, electronics, etc. Its outer dimensions are $1370 \times 1153 \times 212 \mathrm{~mm}$.

Figure 4 Design space for composite floor section (see online version for colours)

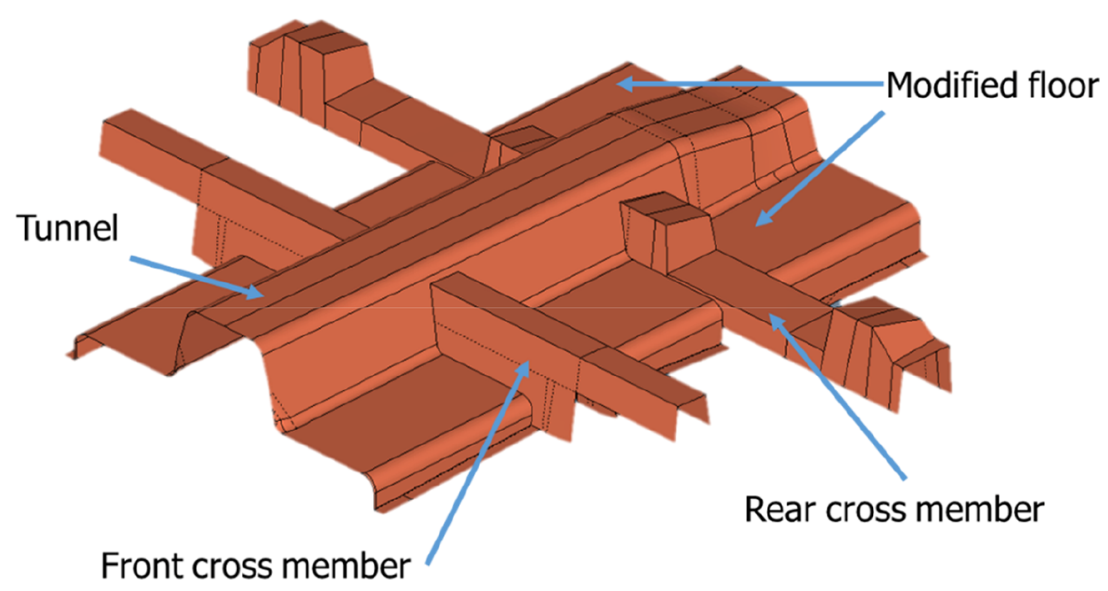

The load case applied corresponds to side pole crash with no deformations in the battery area allowed, i.e., the tunnel and modified floor area (Figure 5). The philosophy is that the steel structure for the normal car should not be changed in order to affect the overall assembly as little as possible. Energy absorption is assumed as taken up in the remaining steel floor structure.

Figure 5 General load case (see online version for colours)

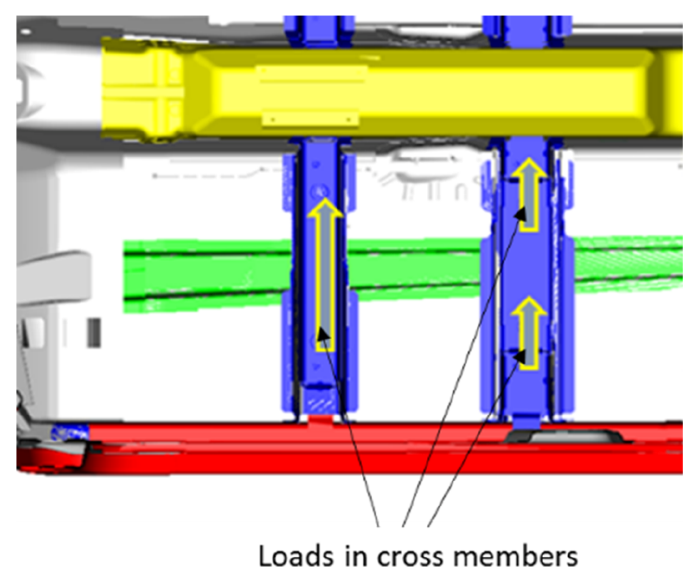




\subsection{Important boundary conditions}

The tunnel and floor section protecting the battery must be a closed section without penetrating structures. No deformation greater than $14 \mathrm{~mm}$ is allowed in the tunnel. A value of weight of $9 € / \mathrm{kg}$ is used in this case study (Mårtensson, Zenkert and Akermo, $2015 b)$. The draping simulations are performed with biaxial fabrics of $0 / 90$ and $+45 /-45$ using multiple seed points and an allowed shear angle of $30^{\circ}$ (Thije, Loendersloot, and Akkerman, 2005). The commercial software Composites Modeller for Abaqus/CAE is used for draping analysis (Anon, 2016).

\section{Results}

Following the given routine as described in Figure 1, the initial requirements and design space analysis define two areas with different structural functional requirements (Mårtensson, Zenkert and Akermo, 2015b); cross members: functional requirement beam stiffness tunnel section, modified floor: functional requirement - panel stiffness.

The material and process selection defines the RTM manufacturing process with continuous high-strength carbon fibre and epoxy resin as the most cost- and weightbalanced material and process selection for the two functional requirements defined. No initial partitioning of the structure is therefore made based on the process selection.

The greater the detailed design resolution, the more local effects and requirements must be taken into account in the partitioning analysis. In this case study, the rigid requirement of a closed tunnel and modified floor will significantly complicate and increase manufacturing operations as well as costs. This level of detail is not captured by the initial partition analysis in the framework. A detailed cost estimate is therefore necessary for an integral structure. There are several options on how to technically solve this problem, of which two are assessed in this work, using a bladder inflated moulding in the cross member or allowing for a sandwich structure cross member. The latter was selected as the most cost-effective solution for maintaining the cross members as a cohesive part of the tunnel section. A detailed cost estimate was therefore performed considering the additional core material and the increased complexity of the lay-up of integrated tunnel cross members. In the partition analysis, this additional cost was removed if a partitioning is used that separates the cross members from the tunnel.

The draping analysis defines potential split lines in order to simplify the manufacturing of the tunnel as shown in Figure 6. The overall results presented in Figure 7 show that when dividing according to Figure 6, the cost is reduced despite the additional assembly process since the complexity of manufacturing operations decreases. At the same time, structural weight increases due to joining, adding adhesive and overlapping laminates. Solving the penalty Eq. (2), based on the given value of weight, the partitioning analysis suggests that the structure should be manufactured in five parts. If divided according to Figure 6, the additional manufacturing costs are avoided at the same time as requirements are fulfilled. Continuing to examine the effects of further splits shows that cost increases rapidly if partitioned into six or more parts, and the solution is therefore not competitive. The proposed partitioning allows for five single curved parts with low geometric complexity (Figure 8), to realise the complete structure. The rear cross member requires patching or multiple preforms to be realised but does not benefit from partitioning into multiple parts. 
Figure 6 Proposed split lines due to the specific requirement for tunnel (see online version for colours)

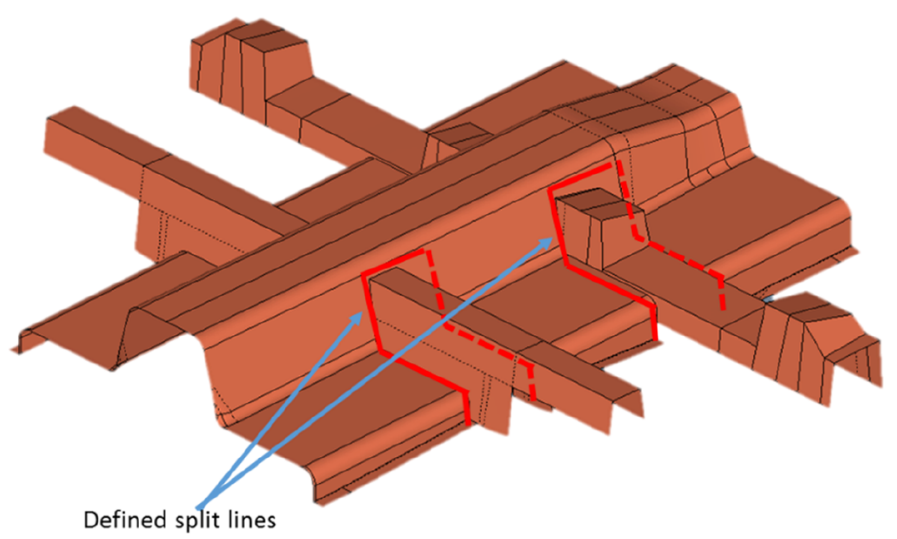

Figure 7 Overall results of cost, weight depending on the partitioning and overall result of the value of weight analysis (penalty function 2)

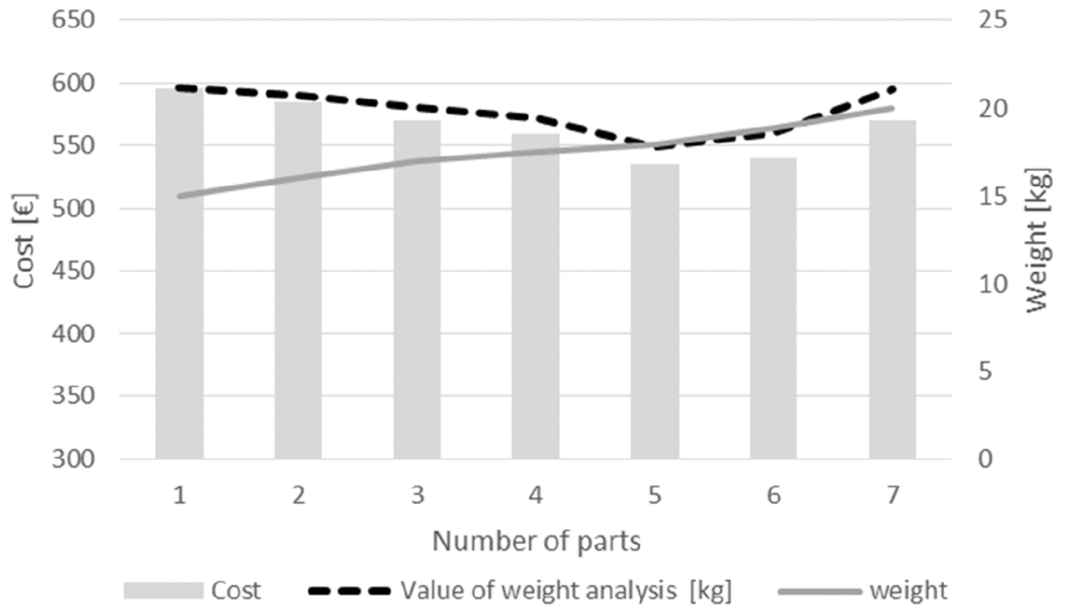

Figure 8 The different parts that realise the complete structure and allow for simple draping (see online version for colours)
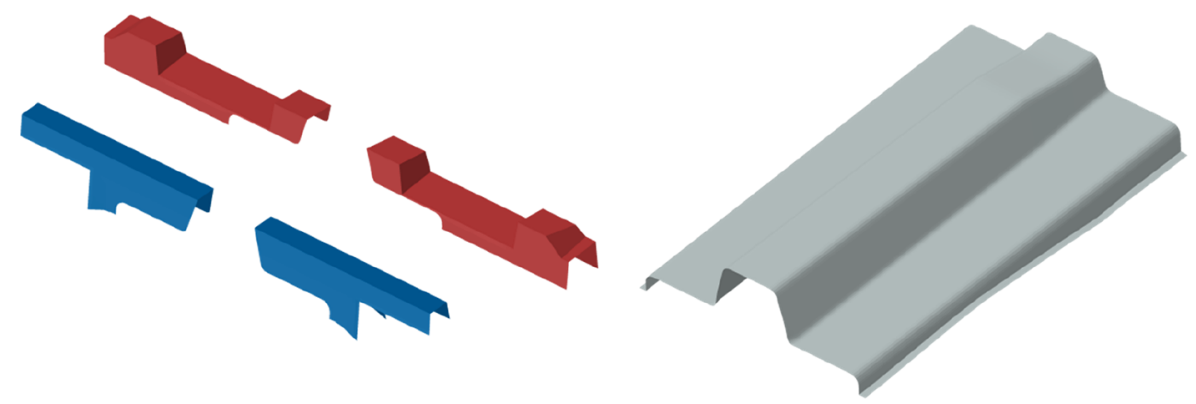
Continuous HS carbon fibre is selected, the beam structure in the cross members is to be structurally designed with the majority of fibres in the beam direction. However, a detailed FEM analysis is required for final structural design and the decision to select either uniform thickness or structurally designed laminate. Whether to use NCF, UD fabric or weave is not addressed in this work. However, the resulting simple geometries of the parts allow for most fabrics to be used.

\section{$5 \quad$ Expert group results}

A group of experts from the automotive industry consisting of material, process and design expertise, was confronted with the same case study. The group followed a classic development routine was initiated with a brainstorm. From this initial input, multiple conceptual ideas were chosen for further examination supported by FEA and cost estimates. The process chosen for the complete structure was RTM and the material system was high-strength (HS) carbon fibre non-crimp fabrics (NCF). Uniform laminates were selected in the complete structure. As seen in Figure 9, the expert group suggested a structure that was divided at the cross members and the tunnel section, to simplify the requirement for a sealed tunnel. A final design consisting of five parts was adopted.

Figure 9 Final conceptual design part split provided by an expert group (see online version for colours)

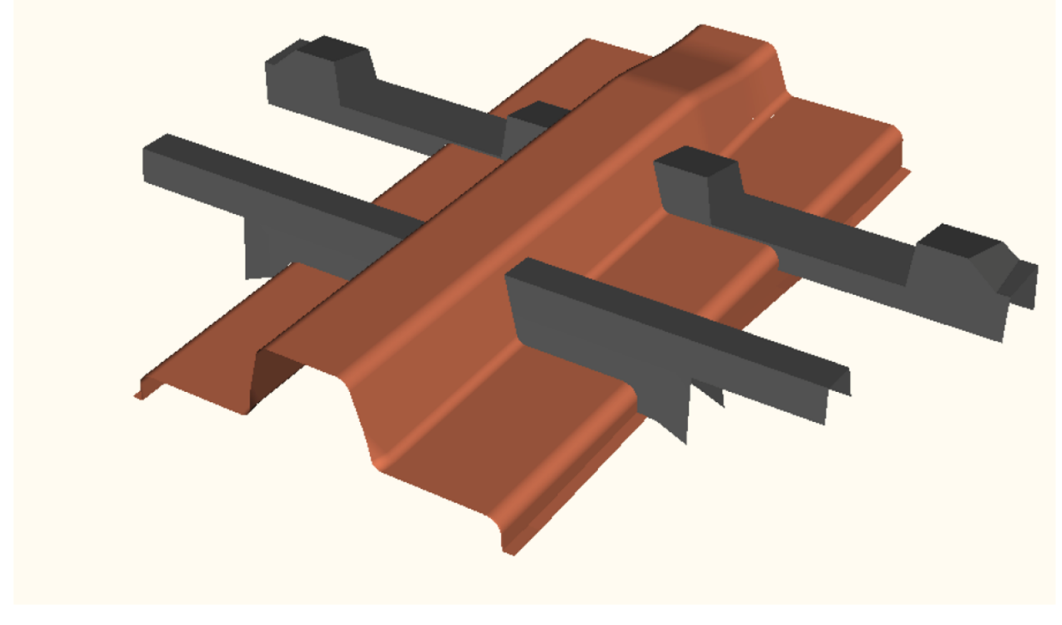

\section{Discussion}

Using a holistic framework as the first step in the design of a very detailed structure with major geometrical constraints was not the primary intention of this study; the aim was instead to understand the contribution of the use of draping simulations in the early stages of a composite component. In fact, the case study presented describes a material exchange from steel to carbon fibre composite without any freedom of redesign, something generally referred to as black metal design philosophy. Despite this, the 
holistic framework seems to work if the detailed requirements and cost estimates are included. In this case, additional costs for complicated manufacturing operations to maintain a closed tunnel section were added to the cost model in the partitioning analysis. The additional cost was connected to the lack of cost-reducing split lines in order to improve the resolution of the framework. Without this detailed assessment, an integral design solution would have been the most cost-effective solution. However, when the resolution was improved, the results from the framework maintained a high degree of relevance from which important information and guidelines for an inexperienced engineer can be defined, e.g., material selection and the importance of limiting complexity and allowing differential design solutions.

Two objectives were in focus when including draping simulations; first to decrease subjective engineering judgement when defining potential split lines for the partitioning of a structure; second, to improve the relationship between choice of fabric and choice of split lines. By introducing draping, the suitable split lines become related to the material and process of choice and the results, therefore, become more material and process dependent. The draping simulation is able to define suitable split lines based on the geometry in relation to the draping potential of the material/fabric. However, one problematic issue concerning the draping simulations is that they, at the moment, are seed point dependent, while most high-volume automotive manufacturing solutions are based on press steps, a single forming operation. Consequently, an accurate analysis of the geometry by draping becomes challenging and requires multiple seed points. Furthermore, as described in Knote (2011), minor changes in seed point positioning and area of investigation result in different draping results, and it becomes important to interpret the results accurately so as to understand that after initial draping complications occur, the surrounding results become obsolete. As seen in Figure 10, by increasing the area in the analysis and with minor changes of seed point positioning, the results become more difficult to interpret. Consequently, engineering skills and composite material competence again become crucial in order to define the most suitable split lines, the largest coherent areas and finally how to divide the structure if proposed. Ongoing development of existing draping simulation software will, however, partially solve this issue in future.

Figure 10 Exemplified results from different seed points and analysis of area size shows the effects on the results from the draping simulation (see online version for colours)

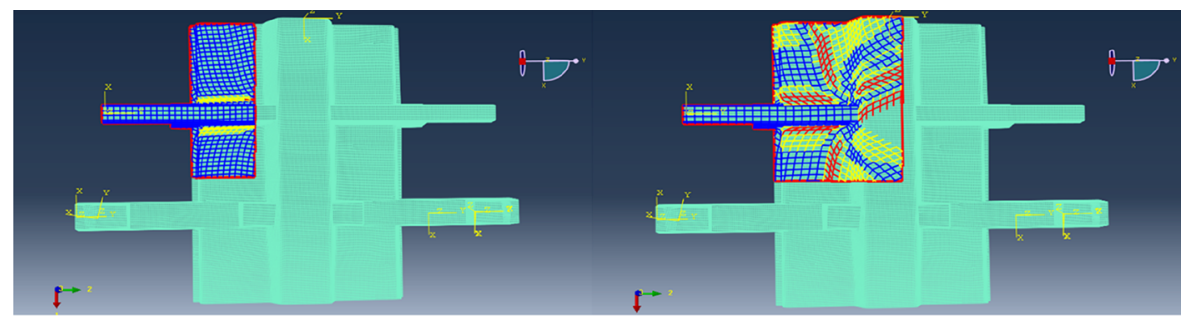

The work of the expert group arrived at the same results as the framework developed here. This is not unusual since the framework includes a mix of processes and design philosophies commonly used by composite experts, although not always that clearly formulated. The results from the framework might be regarded as trivial by composite experts and more or less self-evident. However, achieving these results with a more or 
less blind method is convincing; the method does not only provide important conceptual design assistance but also works as a design routine for the development of structural parts/areas. Also, experts often possess more knowledge in certain areas of manufacturing or material systems and less in others. By applying such a method, a simple verification of material and process selection as well as global design and the cost and weight objective of the development are addressed.

\section{Conclusion}

In this work, a holistic framework for the conceptual design of automotive composite body structures is enhanced by draping simulations. By introducing draping analysis into the method, an improved material and process relationship with the design choice is achieved. The analysis decreases the engineering judgement used in the definition of geometric complexity. However, the complexity of such draping analysis and the great sensitivity of the analysis, dependent on seed points, make such simulation less ideal for the task and too time consuming to be integrated into a development process. Furthermore, engineering judgement is still required to choose from the multiple split lines and to define the greatest coherent area of the parts. A generic forming tool might be much more suited for the purpose of improving draping analysis in the initial framework for conceptual design phase.

\section{References}

2016. Abaqus 6.14 Manual.

Dorf, R.C. and Kusiak, A. (1994) 'Design for manufacturing', In Handbook of Design, Manufacturing and Automation, John Wiley \& Sons, Inc., Hoboken, NJ, pp.123-137.

Fuchs, E., Field, F.R., Roth, R. and Kirchain, R.E. (2008) 'Strategic materials selection in the automobile body: Economic opportunities for polymer composite design', Composites Science and Technology, Vol. 68, No. 9, pp.1989-2002.

Gandhi, M.V., Thompson, B.S. and Fischer, F. (1990) 'Manufacturing-process-driven design methodologies for components fabricated in composite materials', Composites Manufacturing, Vol. 1, No. 1, pp.32-40.

Gutowski, T., Henderson, R. and Shipp, C. (1991) 'Manufacturing costs for advanced composites aerospace parts', SAMPE Journal, Vol. 27, No. 3, pp.37-43.

James, T. (2015) 'Characterization and simulation of structural fabrics-Part 1: A cross-industry review of approaches to composites engineering', Reinforced Plastics, Vol. 59, No. 2, pp.94-99.

Kaufmann, M., Zenkert, D. and Åkermo, M. (2010) 'Cost/weight optimization of composite prepreg structures for best draping strategy', Composites : Part A, Vol. 41, pp.464-472.

Klintworth, J.W. and Long, A.C. (2007) 'The use of draping simulation in composite design', In Composites Forming Technologies, Woodhead Publishing Ltd, pp.277-292.

Knote, A. (2011) 'Draping simulation-the key to low cost high performance net shape parts?' In 5th International CFK-Valley Stade Convention, 7-8 June, Stade, pp.44-53.

Liu, R. and Yang, X. (2001) 'Design for manufacturing', In Handbook of Industrial Engineering: Technology and Operations Management, John Wiley \& Sons, Inc, Hoboken, NJ, pp.1311-1330. 
Marsden, C., Fews, R., Oldroyd, P. and Yousefpour, A. (2011) 'Design for manufacturing-Onepiece, fibre-placed composite helicopter tailboom', In IOP Conference Series: Materials Science and Engineering, 9-10 September, Sheffield, UK.

Mårtensson, P., Zenkert, D. and Akermo, M. (2015a) 'Integral versus differential design for highvolume manufacturing of composite structures', Journal of Composite Materials, Vol. 49, No. 23, pp.2897-2908.

Mårtensson, P., Zenkert, D. and Akermo, M. (2015b) 'Method for the cost-efficient and weightefficient material diversity and partitioning of a carbon fibre composite body structure', Proceedings of the Institution of Mechanical Engineers, Part D: Journal of Automobile Engineering, Vol. 230, No. 1, pp.49-60.

Mårtensson, P., Zenkert, D. and Åkermo, M. (2015c) 'Cost and weight efficient partitioning of composite automotive structures', Polymer Composites.

Mårtensson, P., Zenkert, D. and Åkermo, M. (2015d) 'Effects of manufacturing constraints on the cost and weight efficiency of integral and differential automotive composite structures', Composite Structures, Vol. 134, pp.572-578.

Thije, R.H.W., Loendersloot, R. and Akkerman, R. (2005) Drape simulation of non-crimp fabrics, pp.8-11. 